Opinion

\title{
Consciousness Is a Thing, Not a Process
}

\author{
Susan Pockett
}

School of Psychology, University of Auckland, Auckland, New Zealand; s.pockett@auckland.ac.nz

Received: 30 October 2017; Accepted: 23 November 2017; Published: 2 December 2017

Featured Application: If the theory outlined here is correct, the construction of artificial consciousness will certainly be possible, but a fundamentally different approach from that currently used in work on artificial intelligence will be necessary.

\begin{abstract}
The central dogma of cognitive psychology is 'consciousness is a process, not a thing'. Hence, the main task of cognitive neuroscientists is generally seen as working out what kinds of neural processing are conscious and what kinds are not. I argue here that the central dogma is simply wrong. All neural processing is unconscious. The illusion that some of it is conscious results largely from a failure to separate consciousness per se from a number of unconscious processes that normally accompany it-most particularly focal attention. Conscious sensory experiences are not processes at all. They are things: specifically, spatial electromagnetic (EM) patterns, which are presently generated only by ongoing unconscious processing at certain times and places in the mammalian brain, but which in principle could be generated by hardware rather than wetware. The neurophysiological mechanisms by which putatively conscious EM patterns are generated, the features that may distinguish conscious from unconscious patterns, the general principles that distinguish the conscious patterns of different sensory modalities and the general features that distinguish the conscious patterns of different experiences within any given sensory modality are all described. Suggestions for further development of this paradigm are provided.
\end{abstract}

Keywords: consciousness; electromagnetic; cognitive science; process

\section{Introduction: What Is Meant By ‘Consciousness'?}

In this paper, I deal with two slightly different senses of the word consciousness. First, I examine phenomenal awareness, more commonly known as sensory experience. This includes tastes, sights, sounds, and the feelings of touch, temperature, and to a certain extent, the position in space of various parts of the body. I argue that, while such conscious sensory experiences clearly result from a great deal of unconscious neural processing, the experiences are not themselves processes. Rather, they are transient, three-dimensional patterns of electromagnetism, which are produced using perfectly standard neurophysiological mechanisms during certain phases of the ongoing unconscious neural processing. Secondly, I examine awareness of volition, in the sense of the planning, initiation, and control of voluntary actions. Here, I argue that, although conscious thoughts may well arise during the process of long-term planning, the initiation and carrying out of voluntary actions are completely unconscious processes.

\section{Phenomenal Consciousness Aka Sensory Experience}

The main thrust of this section is to argue that any particular conscious sensory experience is not a process, but rather a thing. Since this assertion directly contradicts a dogma that is so embedded in the zeitgeist of cognitive science that a large majority of cognitive neuroscientists see no need even to state, let alone defend it, I first examine the nature and provenance of this central dogma. 


\subsection{The Central Dogma of Cognitive Science}

The central dogma of cognitive science is 'consciousness is a process, not a thing'. Although the truth of this maxim is taken for granted in the field, its origin is not entirely clear. Tononi and Edelman [1] attribute it to William James, saying "Consciousness, as William James pointed out, is not a thing, but a process or stream that is changing on a time scale of fractions of seconds [2]". However, although James certainly originated the 'stream of consciousness' idea, the closest I can find to a statement by him that consciousness is a process not a thing is a passage in Chapter 6 of Volume 1 of his 1890 magnum opus [2], where we are exhorted to:

"ask ourselves whether, after all, the ascertainment of a blank unmediated correspondence, term for term, of the succession of states of consciousness with the succession of total brain-processes, be not the simplest psycho-physic formula, and the last word of a psychology which contents itself with verifiable laws, and seeks only to be clear, and to avoid unsafe hypotheses". Such a mere admission of the empirical parallelism will there appear the wisest course. By keeping to it, our psychology will remain positivistic and non-metaphysical; although this is certainly only a provisional halting-place, and things must some day be more thoroughly thought out...". [Italics in original].

This hardly seems a ringing endorsement for a maxim that has since achieved such incontestable status. 'Correspondence' is not, after all, the same as identity.

In the post-James era, the study of consciousness was temporarily derailed by the Behaviorist paradigm. The founder of this movement, John B. Watson, announced that 'The time has come when psychology must discard all reference to consciousness; when it need no longer delude itself into thinking that it is making mental states the object of observation.' [3]. However, after thirty or forty years, this approach failed to satisfy. In the late 1950s, Behaviorism was largely supplanted by the functionalist, information processing theories of cognitive science. By 1962, one of the main founders of this cognitive revolution, George Armitage Miller, felt justified in stating unequivocally that "Most psychologists confess that they do not know what consciousness is. They are sure it is not a substance-a material thing - but a process or group of processes, which occurs in some objects and not in others" [4] p. 27.

To be fair, Miller was using this precise form of words to point out the similarities between the prevailing view of psychologists about consciousness and the prevailing view of biologists about life, so it is possible that he himself did not implicitly believe that consciousness is a process, not a thing. Certainly, less than 30 pages later in the same book he makes cogent arguments for the contradictory claim that 'No activity of mind is ever conscious' [4] p. 56. Apparently even the originators of the 'consciousness is a process not a thing' meme were more than a little ambivalent about its accuracy. However it remains true that most cognitive scientists, then and now, are as Miller said sure that consciousness is a process, not a thing.

In fact though, no empirical evidence has ever been offered to support the contention that consciousness is identical with (rather than just usually associated with) any particular neural process. This complete lack of evidence may well be due to the fact that it is not clear what experiment could possibly falsify the claim that consciousness is a particular process. There are plenty of experiments capable of showing that any given process is or is not necessary and/or sufficient for consciousness: see Section 2.2 below for some of them. But this is not at all the same as showing that some process that might in the future turn out to be both necessary and sufficient is actually identical with consciousness. That this intrinsic difficulty is not more widely recognised may in part be due to the sheer unpalatability of the associated implication that the central dogma of cognitive science is actually nothing more than an article of faith, more akin to the Nicene Creed or the Shahada than to a testable hypothesis, let alone a scientific law like those of physics. The Behaviorist project was originally motivated by a certain insecurity or defensiveness about the scientific status of the discipline of psychology: perhaps vestiges of this feeling have lingered. 
In any case, the next section of the present paper describes a number of brain processes that have been claimed by various cogsci theories to be identical with consciousness, but have turned out to be experimentally dissociable from (and thus not even necessary and sufficient for) consciousness.

\subsection{Brain Processes Wrongly Equated with Sensory Consciousness}

In the past, the assumption that sensory consciousness is a neural process has been dogged by one major conceptual error. Essentially, this involves a failure to distinguish phenomenal consciousness per se from a whole series of processes that precede, co-exist with or are consequent upon phenomenal consciousness. Such processes include (but are probably not limited to) top-down aka focal attention, bottom up attention aka the orienting response, decisions regarding report of subjective experience, preparation for movements involved in report, short-term memory, formation, and/or recall of long-term memories, expectation, general arousal, binding, and pretty much anything else that goes on in the 'global workspace' of the brain. The importance of distinguishing between such processes and conscious experience per se has now been pointed out multiple times, (e.g., [5,6] Ch1, [7-9]), but conflation of conscious experience per se with processes that are either necessary but not sufficient for experience, or necessary for the physical movements that are involved in reporting experience has invalidated the interpretation of much early work and to a certain extent remains problematic. A few of the processes that have been mistakenly equated with consciousness are as follows.

\subsubsection{Focal Aka Top-Down Attention}

While focal attention certainly facilitates conscious awareness of a sensory stimulus, it is clear a priori that attention can be paid (to a particular area of space, for example), even when no sensory stimulus ever happens in that location and thus no sensory experience occurs. Hence, attention and consciousness cannot be the same thing. However, this truism did not prevent influential psychologists of the early post-Behaviorist era, like Miller [4] and Neisser [10], from routinely equating the two, with Miller explicitly saying 'the selective function of consciousness and the limited span of attention are complementary ways of talking about the same thing.' [4] p. 49. This error is perpetuated by later workers, e.g., [11,12]. More recently however, experimental work such as that of Wyart and Tallon-Baudry [13] has confirmed the fact that focal attention is dissociable from consciousness (see also Section 4.1.2 of the present paper), so this particular mistake is now probably of historical significance only.

\subsubsection{Processes Occuring in 'the Global Workspace'}

Much of the popularity of attention as a proxy for conscious experience arises from its identification as the spotlight in a theatre metaphor of consciousness. As Baars [14] puts it "The theater metaphor of mind is both ancient and modern. Plato and Aristotle used it, as did the Vedanta philosophers and William James. Modern researchers who have developed scientific theatre models include Herbert A. Simon, Alan Newell and John R. Anderson in cognitive science and Francis Crick in neurobiology. I.P. Pavlov referred to the "bright spot" in the cortex, which integrated all sensory input into one united activity". Actually, it is not at all clear how related either Plato's allegory of the cave or Aristotle's common sense [15] really are to the theatre metaphor of consciousness, and the writers of the Vedanta did not, to my knowledge, say anything that even vaguely resembles this idea. However it is certainly true that the theatre metaphor of consciousness, rebranded as (or perhaps morphed into) the global workspace theory, has been an influential model over the past few decades.

In fact though, the status of both attention and consciousness in global workspace theory is significantly muddled. Baars [16] first says "The central theoretical claim made here is that attention creates access to consciousness". But later in the same paragraph, "consciousness is needed to create access to unconscious processing resources such as the lexicon, autobiographical memory, action routines". So it would seem that consciousness is now recognised not to be attention, because attention is said to create access to consciousness. But consciousness is not identical with the processes that go on in the global workspace either-Baars (rightly in my view) specifically characterises those 
processes as unconscious. So where exactly in this sequence of events does consciousness fit in? It is not clear.

Dehaene and Naccache, who later pick up and run with the global workspace metaphor, are much less confused about the status of consciousness in their theory (albeit ultimately no less wrong about its status in reality). These workers state quite clearly that "global availability of information through the workspace is what we subjectively experience as a conscious state" [17]. But the problem with this is that a plethora of experiments reveal the spreading of information throughout the global workspace to be just another step along the pathway towards the eventual appearance of sensory experience.

As Edelman had long argued [18], feed-back (aka re-entrant aka recurrent) activity carrying information from the global workspace back to the primary and/or secondary sensory areas of the cortex turns out to be absolutely necessary for conscious experience. Edelman's initial conjecture in this regard has now been unequivocally verified by a large number of experiments, in which various areas of brain are temporarily inactivated by focal TMS (transcranial magnetic stimulation) at various times after a sensory stimulus [19-33]. For example, Boyer et al. [34] show that blindsight can be induced by brief inactivation of V1 at 100 ms post-stimulus, and Silvanto and colleagues [30] report that consciousness of motion can be ablated by TMS delivered to any of (i) V1 at 40-60 ms, (ii) V5/MT at $60-80 \mathrm{~ms}$, or (iii) V1 at $80-100 \mathrm{~ms}$ post-stimulus.

Finding (iii) above fits well with the post-stimulus time at which other experimental work suggests that sensory experience occurs $[35,36]$.

\subsubsection{Prefrontal Activity}

For a while activity in the prefrontal region, most of it occurring considerably later than feedback to the primary sensory cortex, was a popular candidate as the neural correlate of consciousness. However this suggestion has also suffered at the hands of experimentation aimed at testing the idea. For one thing, magnetic stimulation of prefrontal cortex affects the voluntary control of bistable stimuli, but not passively experienced bistable stimuli $[9,37]$. Additionally, most frontal activity disappears when no report on sensory experience is required [38-41]. The interpretation of these data is somewhat controversial, with one group arguing that "a few null findings" should not falsify prefrontal theories of consciousness [42]. (Evidence that a prefrontal P3a component still occurs in the absence of any requirement for report after unexpected auditory stimuli [43] is ignored in these arguments, perhaps because P3a is related to the orientation response, which involves involuntary movement). Probably the safest conclusion is that there exists strong evidence suggesting that prefrontal activity is needed for report and voluntary control, but not for phenomenal experience per se.

\subsection{Sequence of Post-Stimulus Neural Activity}

To summarize, the empirically determined sequence of neural events surrounding conscious sensory perception can be interpreted to run roughly as follows:

2.3.1 Neural activity generated by sensory stimulation of peripheral sense organs passes through the thalamus and reaches the relevant primary sensory cortex within the first 20 ms post-stimulus [44].

2.3.2 If and only if this activity is sufficiently intense, it feeds forward and spreads out to what can reasonably be termed a global workspace. If this feed-forward spread or 'ignition' does not happen, conscious perception does not occur [45]. If it does happen, a great deal of arguably unconscious processing takes place in the global workspace, before ...

2.3.3 Feed-back or recurrent activity from the global workspace to the original primary sensory area begins, at around 80 to $100 \mathrm{~ms}$ post-stimulus. If activity in the relevant primary sensory area is blocked at this time, conscious perception of the stimulus does not occur [19-34].

2.3.4 If and only if some bodily action is required to report conscious perception or non-perception of the stimulus, activity takes place in the prefrontal area at a few hundred ms post-stimulus [38-40]. 
This sequence of events strongly suggests that something happens during the second, feed-back pass through primary sensory cortex that (a) is different from what happens during the first, feed-forward pass, and (b) results in conscious experience. The next section explains what this something is.

\subsection{Neurophysiological Difference between Feed-Forward and Feed-Back Activity in Primary Sensory Cortex}

The critical difference between feed-forward and feed-back activity in primary sensory cortex is that feed-back activity produces relatively large local field potentials (LFPs), while feed-forward activity does not. The anatomical and physiological reasons for this difference are explained below.

LFPs are large extracellular electromagnetic (EM) fields, which are produced when many presynaptic axon terminals fire synchronously at chemical synapses on the apical dendrites of neocortical pyramidal cells (Figure 1).

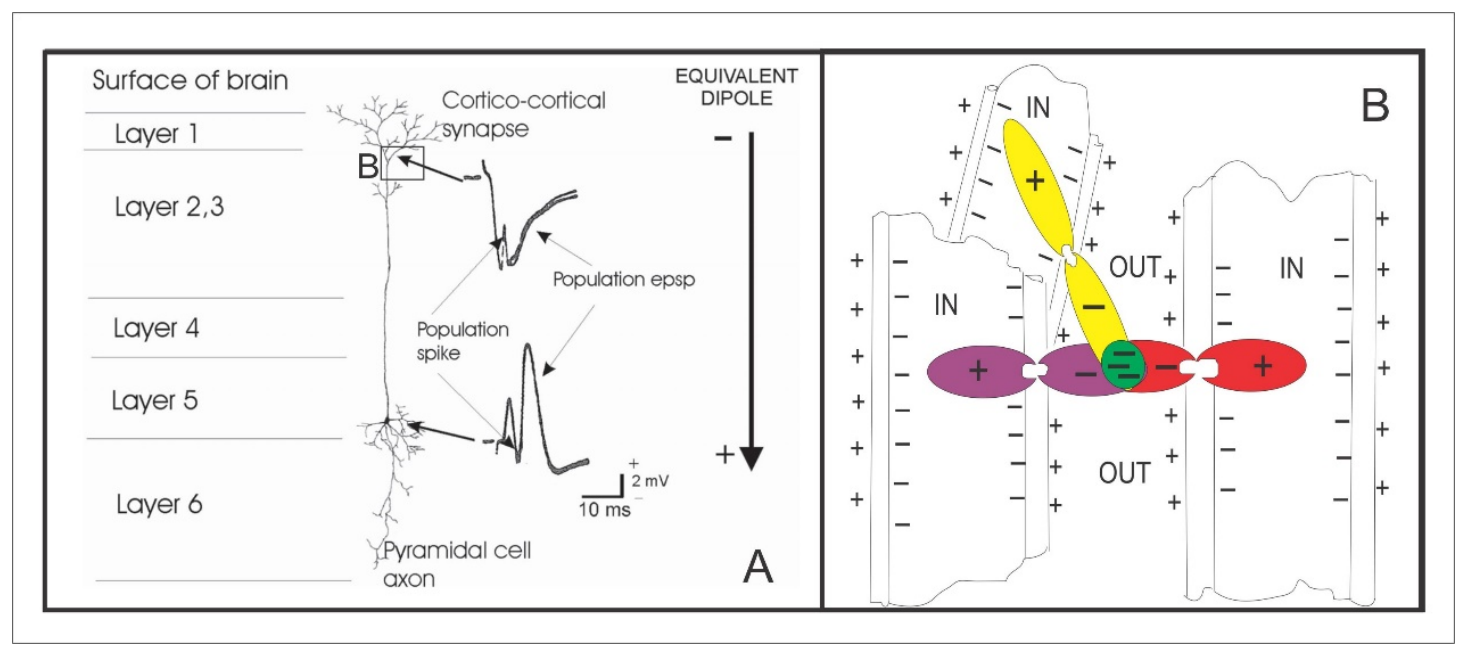

Figure 1. Genesis of local field potentials (LFPs). (A): LFPs are basically population excitatory postsynaptic potentials (EPSPs) that are generated by synaptic action on the apical dendritic tufts of pyramidal cells. When presynaptic terminals (not shown) release neurotransmitter at site B, positive ions enter the postsynaptic dendrite, leaving a transient negative 'hole' in the extracellular fluid. To 'complete the circuit' an equal number of positive ions exit the postsynaptic cell nearer the cell body. This process can be modelled as a large equivalent dipole. (B): Cartoon showing how the negative poles of the smaller dipoles representing entry of positive ions to the postsynaptic dendrites of many synapses can summate to produce the large extracellular voltage transients seen as LFPs (green area). This summation only happens when two conditions are met: (1) many synapses are active synchronously, and (2) the postsynaptic dendrites are anatomically aligned, so that the negative poles of the small dipoles overlap spatially. This explains why large LFPs are not produced during feedforward synaptic activity. Feedforward activity goes mostly through the stellate cells in Layer 4, which do not have anatomically aligned dendrites. Large LFPs are generated only during synchronous feedback synaptic activity, as illustrated in (B).

Figure 1A shows a single pyramidal neuron in the neocortex. Like all neocortical pyramidal cells, this one has a cell body shaped like a pyramid (here positioned at the bottom of Layer 5) and a single, very long, apical dendrite, running from the cell body to the surface of the brain and ending in an apical tuft in Layer 1. The voltage records in Figure 1A show what happens when incoming axons from some other area of brain (not shown) make cortico-cortical synapses at the start of the apical tuft (in the area labelled B in Figure 1A.

Neurotransmitters released by the incoming axons open ion channels in the membranes of the apical dendrites and positive ions flow through these channels from the extracellular fluid to the interior of the dendrite, in accord with the electrochemical gradient between inside and outside. 
The inflow of positive ions leaves a transient negative 'hole' in the extracellular fluid around the synapse. Figure 1B illustrates this process diagrammatically for three adjacent dendrites, showing that the extracellular negativity becomes larger the more synapses are synchronously activated (green area in Figure 1B).

As shown in Figure 1A, the influx of positive ions into each individual dendrite now causes an equivalent number of positive ions to flow out of the cell near the cell body. Thus, a transient "equivalent dipole" between the surface of the brain and deeper layers of extracellular fluid is generated. Again, the green area of Figure 1B shows diagramatically how this dipole becomes much larger if a number of incoming axons fire synchronously. This effect is solely a consequence of basic neuroanatomy. It occurs because all of the apical dendrites are anatomically aligned.

The critical difference between feedback and feedforward activity is also solely a consequence of neuroanatomy. It is that (as shown in Figure 1) feed-back activity occurs at Layer 1 cortico-cortical synapses, while, in contrast, feedforward thalamo-cortical connections go mainly through the stellate cells of Layer $4[46,47]$. Synapses on stellate cells do not produce large local field potentials, simply because stellate cells are star-shaped-their dendrites are not anatomically aligned. This lack of anatomical alignment means that the transient extracellular negativity resulting from activity at any given thalamocortical synapse tends to be cancelled out by the cell-body-adjacent positivities that result from the activity of neighboring synapses.

The result of all this is that feed-forward, thalamo-cortical synapses in the primary sensory cortex produce action potentials (recorded extracellularly as 'spikes, or 'single units') but not local field potentials. On the other hand, feed-back, cortico-cortical synapses in the primary sensory cortex do produce local field potentials.

\subsection{What Manner of Thing Is Consciousness?}

We have seen above that relatively large spatial patterns of LFPs are produced during feed-back activity at synapses in primary sensory cortex-and conscious sensory experiences are also produced during feed-back activity at synapses in primary sensory cortex. It is thus a reasonable hypothesis that conscious experiences may actually be transient spatial patterns of LFPs: in other words, transient spatial patterns of electromagnetism.

Experimentally speaking, this idea immediately makes sense of a great deal of initially confusing evidence showing that action potentials in the primary sensory cortex do not correlate with consciousness [48-54], while LFPs in the primary sensory cortex do [55-57]. Individual $\mathrm{Na}+\mathrm{K}+$ action potentials are of short duration and, at least as measured extracellularly, do not propagate far from their site of generation. So although the extracellular spikes (aka single units) that are generated by many neurons firing synchronously can have a measurable effect on very high frequency LFP components, spikes in general contribute very little to the relatively slow EM patterns that constitute the bulk of an LFP [58,59].

Philosophically speaking, the idea that conscious experiences are spatial electromagnetic patterns has the major advantage that it solves an underlying problem that has always beset the topic of consciousness. The problem is basically an intuitive one-we want consciousness to be part of the physical world, but it just seems wrong to identify conscious experiences with matter. The answer to this bothersome conundrum turns out to be ridiculously easy: matter is not the only kind of physical entity. Electromagnetism is also an undeniable part of the physical world.

In general terms, the parallels between consciousness and electromagnetism are striking. First, consciousness appears to be produced by the brain-and it is well accepted that patterns of electromagnetism are produced by the brain. Secondly, consciousness appears on the face of it to share the same area of space-time as the brain-and it is well accepted that electromagnetic fields share the same area of space-time as matter.

The clinching parallel between consciousness and electromagnetism seems initially to be the observation that consciousness has the ability to act on its own brain. There certainly exists a great 
deal of evidence that brain-generated EM fields can and do act back on their own brains, e.g., [60-69]. This appears to solve the main problem which has always bedeviled philosophical dualism. Traditional substance dualism is routinely rejected on the grounds that it is hard to see how a non-material substance could act on the brain. But here we have a particular kind of non-material substance (electromagnetism) that clearly does act on the brain. Every working neurophysiologist has personal, hands-on experience of making brain tissue respond to experimentally applied EM fields.

But, there is a catch. All of the empirical reports cited above involve the back-action of brain-generated fields on the very neurons that generated those fields in the first place. This gels with the fact that the brain-generated fields proposed by the EM field theory of consciousness as being conscious [70] involve electric dipoles, which means that the strength of the field falls off not with the square of distance from their site of generation, but with the cube of distance from their site of generation [71]; which in turn means that these fields essentially cease to exist as spatial patterns within a few $\mathrm{mm}$ of their site of generation [72]. This fact has two important consequences: (1) in practical terms, in order to measure such patterned EM fields the measuring electrode has to be located not more than a couple of mm away from the site of generation of the field; but also (2) given that the neurons that initiate bodily actions generally reside much further than a couple of $\mathrm{mm}$ from the site of generation of putatively conscious EM patterns, it is hard to see how such patterns could be the proximal cause of bodily actions. They could certainly act on the neurons that generated them (as indeed they must if it is to be possible to report the existence of a conscious experience at all). But any consequent bodily action must then be implemented by standard neurophysiological mechanisms, which are themselves unconscious. Our putatively conscious EM patterns can not act directly on the neurons that are the proximal (i.e., immediate) cause of bodily actions. If these patterns can not be the proximal cause of bodily actions, while consciousness IS the proximal cause of bodily actions, these patterns can not be consciousness. The EM field theory of consciousness must be wrong.

However, this brings us to the next section of the present paper, in which the idea that consciousness really is the proximal cause of 'voluntary' actions is seriously questioned.

\section{Are the Neural Processes That Result in Voluntary Actions Conscious?}

It is now fairly well accepted, even by those who continue to insist that consciousness is a process not a thing, that most if not all of the neural processing of sensory input is done unconsciously. Less consensus presently surrounds the idea that the neural processes culminating in bodily action are similarly unconscious.

Much of the lack of clarity in this matter stems from a failure to separate the long-term planning of voluntary actions from the actual doing - the proximal initiation and control一of those actions. While long-term planning of action may well be conscious, there is now a good deal of evidence that the proximal initiation and ongoing control of actions is not.

\subsection{The Anatomy of Action}

As summarised by Figure 2 in Reference [73], the long-term planning of action takes place in the posterior parietal and prefrontal cortices. Anatomically, these regions comprise six-layered neocortex that is similar to that seen in primary sensory areas. In contrast, the areas of cortex that probably subserve the initiation of actions are regions described by the early anatomists as 'agranular', meaning that anatomically, they do not have a Layer 4. Once initiated, actions are controlled largely by the cerebellum, which although layered does not have pyramidal cells like those in neocortex at all.

The question of how or whether consciousness is involved in the initiation of actions has been the subject of a good deal of experimentation over the last decade or so. 

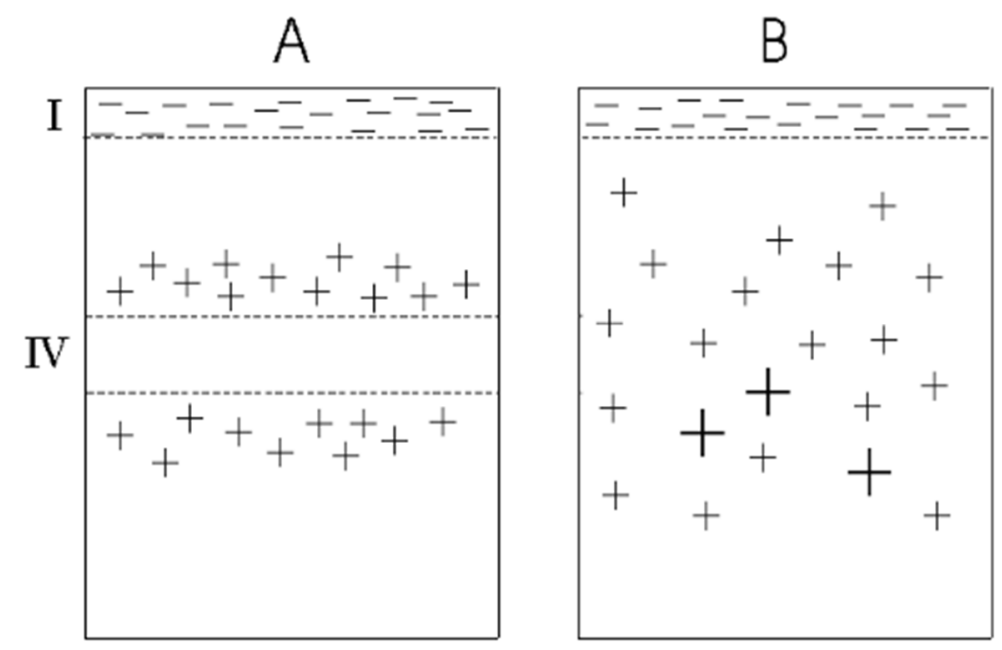

Figure 2. Schematic diagram of proposed electromagnetic (EM) field shapes characterising (A) conscious and (B) unconscious fields. Roman numerals indicate cortical layers: Layer I is at the surface of the cortex (After [71]). This represents a snapshot of one instant in time: the pattern is assumed to change on a time scale concomitant with the rise and fall of the conscious experience, as in the right hand panel of Figure 3.

\subsection{Experimental Evidence on the Relationship of Consciousness to Action}

Essentially all of the experimental evidence summarised here [70,71,73-78] suggests that people are not conscious of exactly when they initiate voluntary actions - or indeed of why, or even whether they initiated the action at all. For example, when subjects were instructed to stop a moving cursor [79] or move a pair of rubber hands [80] whenever they felt like it, they were significantly unsure whether they or the experimenter had caused any particular stop or movement. The confluence of evidence in this regard suggests that the initiation and control of voluntary actions is not accessible to consciousness, and that our awareness about such matters comes largely from any sensory feedback that might result from our actions. With regard to the rationale behind our behavior, we readily come up with plausible explanations of why we did things, but these are actually only inferences, which are about as accurate as our inferences about why someone else did what they did.

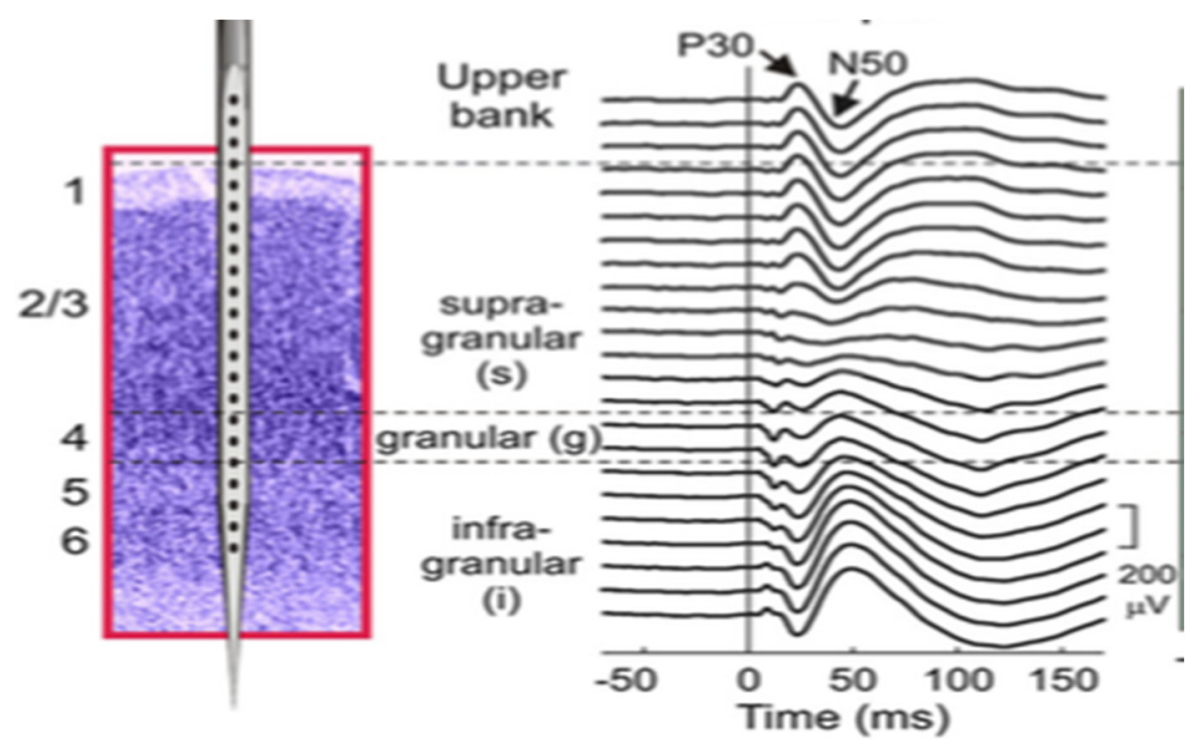

Figure 3. Laminar profile of LFPs in auditory cortex of awake monkeys (after [81]). 
Although the experimental evidence leading to these conclusions is strong, the conclusions themselves are sufficiently unpalatable that a number of objections to them have been raised. For example, various of the philosophers contributing to [76] argue that the relevant experiments should be ignored because (a) they put people in abnormal situations (as indeed do all experiments), or (b) they show that some but not ALL actions are initiated unconsciously (the problem of induction has always been tricky), or (c) we do not yet know enough about the neurophysiology of action to interpret the experimental evidence properly (an argument that would carry more force if its author did not then conclude that enough is already known to support the prescientific intuition that consciousness does cause action).

In any case, both psychological experiments on the initiation and control of voluntary actions and direct stimulation of the motor cortex of awake neurosurgical patients combine to support the conclusion that most of the processing underpinning the initiation of actions is unconscious-and more radically, that consciousness usually does not accompany either the initiation or the control of voluntary actions at all. From the point of view of the proposal that conscious experiences are patterned electromagnetic fields, this again suggests that it should be instructive to ask what anatomical feature distinguishes motor areas of cortex. As we have just seen, the motor areas of cortex do not produce conscious experiences, while sensory areas of cortex do. Hence, any major anatomical difference between motor and sensory areas might provide an important clue as to the structural differences between conscious and unconscious EM fields.

\subsection{Distinguishing Anatomical Feature of Motor Cortex and Predicted Characteristics of Conscious vs. Unconscious Fields}

The anatomical feature distinguishing motor areas of the neocortex from non-motor areas is the lack of a Layer 4. This led [71] to the prediction that the three-dimensional LFP pattern that is produced by cortico-cortical synapses on motor cortical pyramidal cells might differ from that which is produced by cortico-cortical synapses on sensory pyramidal cells as shown in Figure 2.

Figure 2A shows a surface layer of negative-going potentials resulting from the action of feed-back synapses on the apical tuft of pyramidal cell dendrites, and two layers of positive-going potentials lower down in the radial direction. The top layer of positive-going potentials in Figure 2A was postulated to result from the activation of Layer I synapses on pyramidal neurons with cell bodies in Layer III and the bottom layer of positive-going potentials from activation of Layer I synapses on pyramidal neurons with cell bodies in Layer $5 / 6$.

In fact, however, when Kajikawa and Schroeder [81] actually measure the radial distribution of LFPs in the auditory cortex of awake monkeys, the result is illustrated by Figure 3.

Figure 3 clearly shows that the result of the initial, feed-forward pass of activity through the primary auditory cortex of awake monkeys is (as predicted), a very small LFP originating in the granular layer (layer 4). Because it is so small, this LFP spreads vertically for not more than a couple of hundred $\mu \mathrm{m}$. However, the later, much larger, negative-going potential (labelled N50 in Figure 3), which arises directly from activity at feed-back synapses in Layer I, spreads much further down through the cortical layers than predicted in Figure 2. Additionally, the positive-going return currents consequent on the activity of these Layer I synapses are essentially confined to Layers $5 / 6$, indicating that the relevant cell bodies live solely in sub-granular layers. Further investigation of the local circuits that are involved in feed-back activity would clearly be interesting.

The prediction illustrated in Figure 2B has not yet been tested at all. From this point of view, it would be most interesting to measure in various areas of motor and premotor cortex the laminar profiles of the 'readiness potentials' preceding motor actions.

\subsection{Long-Term Planning of Voluntary Actions}

All of the experimental data (referred to above) suggesting the unconscious initiation of voluntary actions arise from experiments in which the actions under study were planned well before the actual 
experiment. Long-term planning of actions occurs in the parietal and/or prefrontal cortex, areas that anatomically do have a layer 4 . Hence the predictions above suggest that the claim by Newell and Shanks [82] that "inadequate procedures for assessing awareness, failures to consider artifactual explanations of "landmark" results, and a tendency to uncritically accept conclusions that fit with our intuitions have all contributed to unconscious influences being ascribed inflated and erroneous explanatory power in theories of decision making" may well be correct.

\section{The Electromagnetic Field Theory of Consciousness}

The idea that consciousness is not a process per se, but rather a thing that is produced during some phases of unconscious processing, is embodied by the hypothesis that conscious experiences are transient, three-dimensional patterns of LFPs-in other words, that they are spatially patterned EM fields. The proposed characteristics of such fields as described in this section are presently a mixture of existing evidence and speculation.

\subsection{Proposed Characteristics of Conscious EM Fields}

4.1.1 First, it is clear that in order to be conscious, a field has to be stronger than a certain basic minimum. Evidence supporting this claim includes a report of binocular rivalry studies using MEG [83], which to quote the authors shows that

"1. Neural responses to rivalrous visual stimuli occurred in a large number of cortical regions, both when the subject consciously perceived the stimuli and when he did not.

2. Responses evoked by a stimulus over a large portion of the scalp were stronger when the subjects were conscious of it than when they were not."

On the basis of a comparison of the analytic power of waking and unconscious ECoG data measured at a series of wavelengths and bandwidths, Pockett and colleagues [84] estimate that the minimum analytic power necessary for consciousness is of the order of $50 \mu \mathrm{V}^{2} / \mathrm{Hz}$ over the frequency range $1-100 \mathrm{~Hz}$.

4.1.2 However, simple power is clearly not enough. Dreamless sleep involves huge EEG slow waves and no consciousness at all. Also, not every evoked potential results in consciousness. For example, respectably sized ECoG evoked potentials can be recorded from visual cortex in response to auditory stimuli that did not evoke any visual experience at all [85]. (To return to the material in Section 2.2, these unconscious evoked potentials recorded over the visual cortex may well represent the physical instantiation of focal attention. If a sound is heard as originating from a particular location in space, it is advantageous in evolutionary terms to boost the likelihood that any visual event in the same location will be noticed, so the audiovisual pathway is activated and the relevant area of visual space automatically and unconsciously primed. Hence, attention is an unconscious process that serves to enable consciousness, but is not identical with it).

So in order to be conscious, brain-generated EM patterns not only have to be strong enough: they also have to be spatially patterned in some way. One speculation is that the pattern distinguishing conscious from unconscious fields may be as shown in Figure 2. Initial tests suggest that this speculation may be partly right, but further tests are obviously needed.

4.1.3 It is suggested that different modalities of conscious experience are also differentiated by spatial patterning of LFP fields in the radial direction [70]. The rationale here is that it has been known for over a century that differences in the relative thickness of the various layers of neocortex is diagnostic of areas that are devoted to particular sensory modalities. Thus, it seems reasonable to expect that radial patterns of LFPs may differ depending on the area of cortex that generates them, which, in turn, depends on the sensory modality. Again, the testing of this speculation would be relatively straightforward technically.

4.1.4 Spatial patterning of putatively conscious fields in the tangential direction (resulting from differences between the activity of adjacent anatomical columns) has been shown in animal experiments to define different experiences within a given sensory modality [86-89]. 


\subsection{A Manifesto for Future Experimental Testing of the EM Field Theory of Consciousness}

4.2.1 In order to measure the spatial patterns that are proposed above as constituting consciousness, physics dictates that it is necessary to record from microelectrodes that are positioned less than a mm from the synapses producing any given section of the pattern [72]. In practice, this means recording directly from the neocortex of waking subjects, using 3-dimensional arrays of electrodes consisting of a large number of multi-contact shanks that are arranged in a closely spaced grid. In recent years, both suitable electrodes and the ability to record from hundreds of contacts simultaneously have become commercially available, so the time is ripe technically for investigation of the proposals in Section 4.1.

The question of whether animals or human neurosurgical patients should be the subjects of such recordings is moot. Animal subjects in some ways provide easier access, but their inability to report verbally on their conscious experiences is a significant problem that probably outweighs this advantage.

4.2.2 Every scientific theory worth its salt should be falsifiable. One critical experimental test of the idea that conscious experiences are EM patterns was suggested five years ago [70], but repeated attempts by the author to find a venue in which to carry out the experiment have so far proved unsuccessful. This test involves clamping or zeroing out putatively conscious EM fields using an extracellular version of the classic voltage clamp technique $[90,91]$. To fit in with modern standard of care practice in epilepsy clinics (where electrodes are sometimes implanted for the clinical purpose of localising both epileptic foci and eloquent cortex prior to excising the first and sparing the second, in order to produce an acceptable cure for the patient's epilepsy), the clamp would best be implemented in software rather than hardware. The basic aim would be to inject into the extracellular fluid, at a spot predicted by the theory to underpin the simplest possible experimentally inducible experience (for example the sound of a click), sufficient current to just prevent the change of voltage that would normally constitute the local field potential evoked by the auditory stimulus. If this clamp is implemented successfully, it should be possible to compare the current injected by the clamp with the LFP produced by the stimulus in the absence of the clamp, to prove that the clamp does not affect ongoing synaptic activity. If it does not, the current waveform will be a perfect inverse copy of what would normally be the LFP. To complete the experiment, the patient is then simply asked whether or not they heard a click. If they always hear a click with this particular auditory stimulus in the absence of a clamp, but reliably fail to hear one in the presence of the clamp, the only thing that will have been altered by the clamp is the EM field. The current measurement mentioned above will have ensured than synaptic activity per se-the release of neurotransmitter from the presynaptic terminal, interaction of transmitter with postsynaptic receptors, consequent inflow of ions from the extracellular fluid into the postsynaptic dendrite (potentially leaving a transient 'hole' in the extracellular fluid, which hole has here been filled by the injected current) -all continued as normal. So the EM pattern and only the EM pattern has been removed.

The crucial difference between this experiment and the sledgehammer ablation of synaptic activity by a blast of TMS delivered to the scalp, or directly injected current of the sort routinely used clinically to locate eloquent cortex, is the intensity of the current injection. Too much and you stop synapses from working altogether, by depolarising them (this is the desideratum during clinical work to localise eloquent cortex, for example). Too little current injection and you still see an LFP. The Goldilocks moment comes when the LFP is ablated and the waveform of the injected current resembles an inverted LFP. If this condition prevents (or even significantly alters) the conscious experience, that would constitute persuasive evidence in support of identity between conscious experience and LFP pattern.

4.2.3 Any manifesto for future experimental testing of a theory should ideally include mention of experiments that would NOT repay further effort, since they have already been comprehensively done, with results that support the theory. In the present case, one major group of such experiments stems from Horace Barlow's 1972 paper "Single units and sensation: A neuron doctrine for perceptual psychology?" [92]. The self-titled "first dogma" of this paper specifically asserts that the significant 
level of description for the study of how the brain represents sensory information is the individual cell. In 1972, use of the word 'consciousness' was regarded by neurophysiologists as unacceptably New-Age, but the word 'perception' did sterling service in its place. The central proposition of Barlow's paper was: "our perceptions are caused by the activity of a rather small number of neurons selected from a very large population of predominantly silent cells. The activity of each single cell is thus an important perceptual event, and it is thought to be related quite simply to our subjective experience". Barlow stops short of explicitly proposing identity between subjective experience and the behaviour of single cells-in fact he openly acknowledges that not all single neural events are even "related quite simply to" conscious perception, that it is not at all clear why some are and others are not and that the concept of a pontifical or grandmother cell, which appears on the face of it to be a logical extension of the single neuron doctrine, is untenable (a case later made in considerable detail by others $[93,94]$ ). However, Barlow's influence in the 1970s was such that his neuron doctrine essentially defined the paradigm that was adopted by a generation of neurophysiologists for the study of perception.

Certainly, the experiments that led to the neuron doctrine [95-97] were methodologically ground-breaking, to the extent that they later garnered Nobel Prizes for Hubel and Wiesel. However, Barlow's conclusion from their results that the rare neurons whose firing would turn out to be "related quite simply to" conscious experience were the complex and hypercomplex cells at the top of the visual feedforward heirarchy turned out to be true in one sense, but seriously misleading in another sense. It was true in that later findings showed that (a) $90 \%$ of neurons in the temporal cortex (the habitat of complex and hypercomplex cells) predict perception during binocular rivalry, while only $18 \%$ of units in V1 modulate their firing in line with perception $[54,98,99]$, and (b) individual neurons that fire only in response to pictures of specific people are found in the human temporal lobe, but not in V1 [100]. However, given the evidence (cited in Section 2.2.2 of the present paper) that recurrent activity in primary sensory cortex is necessary for sensory consciousness, the now abundant evidence that the firing of neurons in primary sensory cortex does NOT correlate with consciousness conclusively falsifies the idea that the firing of individual neurons is even the proximal cause of conscious experience, let alone identical with it. Evidence for the lack of correlation between conscious experience and the firing of neurons in primary sensory cortex includes: (i) we can not consciously perceive which eye a stimulus is presented to, even though V1 contains single unit representations of this information [101] (ii) if a grating has a very high-frequency or is crowded by surrounding gratings its orientation cannot be perceived, even though this information is represented in V1 [48,49]; and, (iii) single cells in V1 differentiate between local depth cues even when those cues do not give rise to an overall depth percept [50]. Many more such examples are summarized by Rees [102], who points out that most of them probably reflect firing during the feedforward pass of activity through V1. Perhaps the critical finding in this regard is that single cell firing rate and high frequency LFPs in V1 do not correlate with consciousness, while low frequency LFPs and fMRI signals do [57,103].

4.2.4 Another group of experiments that are already well done in relation to the neural correlates of consciousness are concerned with the correlation between consciousness and synchronous neural activity. Empirically, long-distance phase synchrony between different areas of the brain seems to be necessary [104-107] (albeit not sufficient [108-110]) for consciousness. The EM field theory of consciousness predicts exactly this, in that large enough LFPs are only produced by the synchronous firing of many presynaptic axons (Figure 1B), the cell bodies of which are often a considerable distance from their terminals.

\subsection{Implications for the Construction of Artificial Consciousness}

Functionalist theories like those espoused in cognitive science have always been attractive to those who are interested in the construction of artificial consciousness, because they suggest that all one needs do to reproduce a conscious experience is reproduce whatever abstract process the experience is seen as being idential with—any instantiation of the process will do [111]. The analysis in the present paper suggests that this paradigm is fundamentally misguided. The electromagnetic field 
theory of consciousness posits that conscious experiences are not abstract entities, but actual things: spatially patterned electromagnetic fields. Of course biologically, these EM fields are produced by neural processes (using that word in the abstract sense rather than the dendritic sense). But there is no getting around the fact that, as used in the central dogma of cognitive science and functionalism, 'process' is an abstract noun. This often overlooked fact is actually implicit in the dogma itself: "Consciousness is a process, NOT A THING". Thus, equating consciousness with a process is equating consciousness with an abstract entity.

The EM field theory says that consciousness is not an abstract entity. It is a thing. It's just that, unlike material things, this kind of thing can (and routinely does) change on a time-scale of fractions of a second. It was almost certainly the fact that macroscopic material things do not change on this time scale, while consciousness clearly does, that led to the perfectly reasonable conviction that consciousness is not a material thing. The problem then was simply a failure to take the small further step of recognising that material things are not the only kinds of thing that exist. Or, if you think (as I do not) that the quantum spatial scale is of relevance to consciousness, matter fields are not the only kinds of field that exist.

With regard to the possibility of producing artificial consciousness, it is relatively easy to produce EM fields artificially. The EM field theory of consciousness predicts that correctly configured EM fields that are produced by hardware will be just as conscious as similarly configured fields that are produced by wetware. So according to this theory, artificial consciousness is definitely on the cards. However, the necessary research program underpinning this project will be fundamentally different from that is presently espoused by cognitive neuroscience.

Two separate steps will be necessary, although at least initially these are not interdependent so they could be pursued concurrently.

First, it will be necessary to develop techniques for generating spatially patterned EM fields using hardware instead of wetware. The most obvious way of doing this in the present context would essentially be to recreate the structural anatomy of the brain in silicon. But, that would be a formidably complex project. A more intriguing method would be to use the constructive and destructive interference of a number of projected beams of radiation to create spatial patterns of EM intensity in a remote location.

The second requirement is clearly to measure in living subjects the spatial patterns of EM intensity that need to be reproduced. A general methodology for that part of the project is outlined in the body of the present paper. Analyses such as that in reference [112] raise the possibility that the spatial resolution of the required measurements may turn out to be an order of magnitude greater than those proposed above. However, other arguments suggest that evolution has been more forgiving in this regard [72].

\subsection{Implications for Neuroscience}

The construction of artificial consciousness is an exciting (or perhaps frightening, depending on your viewpoint) project, but any realistic implementation of it is probably too far in the future to matter in the here and now. In the meantime, the EM field theory of consciousness has far more immediate implications, both in terms of clinical practice and in terms of the kinds of basic experimentation that will repay future investment.

Clinically, the identification of conscious experience in patients who are physically unable to communicate is a critical issue in medicine. Scalp EEG goes some way towards the goal, but the sheer distance between the brain and scalp makes the identification of detailed EEG correlates of conscious experience problematic at best, and impossible at worst [72]. There is urgent need for a reliable measure of the presence of sensory consciousness. The experiments proposed in Section 4.2.1 could result in production of a miniaturised device, deployed by drilling a small, temporary hole in the skull and inserting a discrete electrode array, which would unequivocally test for the presence of awareness of a specific, simple sensory stimulus. Conversely, if the EM field theory of consciousness is 
right, unwanted sensory experiences like chronic pain could be treated by measuring the associated brain EM field and then intervening to cancel it out, by imposition of an inversely patterned field (on the same principle as that used by noise-cancellation headphones on sound waves).

With regard to basic neuroscience, the message is simple. Single cell work has had its day. The topic of the future is the LFP.

Acknowledgments: No funding, either for salary or grant support, has been received for this study. No funds for covering the costs to publish in open access are available to the author.

Conflicts of Interest: The author declares no conflict of interest.

\section{References}

1. Tononi, G.; Edelman, G.M. Consciousness and complexity. Science 1998, 282, 1846-1851. [CrossRef] [PubMed]

2. James, W. Principles of Psychology; Henry Holt: New York, NY, USA, 1890; p. 1393.

3. Watson, J.B. Psychology as the behaviorist views it. Psychol. Rev. 1913, 20, 158-177. [CrossRef]

4. Miller, G.A. Psychology: The Science of Mental Life, 1st ed.; Harper and Row: New York, NY, USA, 1962.

5. Velmans, M. Is human information processing conscious? Behav. Brain Sci. 1991, 14, 651-669. [CrossRef]

6. Pockett, S. The Nature of Consciousness: A Hypothesis; iUniverse: New York, NY, USA, 2000; p. 212.

7. Bachmann, T. Finding ERP-signatures of target awareness: Puzzle persists because of experimental co-variation of the objective and subjective variables. Conscious. Cognit. 2009, 18, 804-806. [CrossRef] [PubMed]

8. Aru, J.; Bachmann, T.; Singer, W.; Melloni, L. Distilling the neural correlates of consciousness. Neurosci. Biobehav. Rev. 2012, 36, 737-746. [CrossRef] [PubMed]

9. De Graaf, T.A.; Hsieh, P.J.; Sack, A.T. The 'correlates' in neural correlates of consciousness. Neurosci. Biobehav. Rev. 2012, 36, 191-197. [CrossRef] [PubMed]

10. Neisser, U. Cognitive Psychology; Appleton-Century-Crofts: East Norwalk, CT, USA, 1967.

11. Baars, B.J. A curious coincidence? Consciousness as an object of scientific scrutiny fits out personal experience remarkably well. Behav. Brain Sci. 1991, 14, 669-670. [CrossRef]

12. Merikle, P.M.; Joordens, S. Parallels between perception without attention and perception without awareness. Conscious. Cognit. 1997, 6, 219-236. [CrossRef] [PubMed]

13. Wyart, V.; Tallon-Baudry, C. Neural dissociation between visual awareness and spatial attention. J. Neurosci. 2008, 28, 2667-2679. [CrossRef] [PubMed]

14. Baars, B.J. In the Theater of Consciousness: The Workspace of the Mind; Oxford University Press: New York, NY, USA, 1997.

15. Baars, B.J. A Cognitive Theory of Consciousness; Cambridge University Press: New York, NY, USA, 1988.

16. Baars, B.J. Some essential differences between consciousness and attention, perception and working memory. Conscious. Cognit. 1997, 6, 363-371. [CrossRef] [PubMed]

17. Dehaene, S.; Naccache, L. Towards a cognitive neuroscience of consciousness: Basic evidence and a workspace framework. Cognition 2001, 79, 1-37. [CrossRef]

18. Edelman, G.M. Group selection and phasic reentrant signaling: A theory of higher brain function. In The Mindful Brain: Cortical Organization and the Group Selective Theory of Higher Brain Function; Edelman, G.M., Mountcastle, V.B., Eds.; MIT Press: Boston, UK, 1978; pp. 51-98.

19. Lamme, V.A.F.; Supèr, H.; Spekreijse, H. Feedforward, horizontal and feedback processing in the visual cortex. Curr. Opin. Neurobiol. 1998, 8, 529-535. [CrossRef]

20. Lee, T.S.; Mumford, D.; Romero, R.; Lamme, V.A.F. The role of primary visual cortex in higher level vision. Vis. Res. 1998, 38, 2429-2454. [CrossRef]

21. Pollen, D. On the neural correlates of visual perception. Cereb. Cortex 1999, 9, 4-19. [CrossRef] [PubMed]

22. Pollen, D. Explicit neural representations, recursive neural networks and conscious visual perception. Cereb. Cortex 2003, 13, 807-814. [CrossRef] [PubMed]

23. Pollen, D. Fundamental requirements for primary visual perception. Cereb. Cortex 2008, 18, 1991-1998. [CrossRef] [PubMed]

24. Fahrenfort, J.J.; Scholte, H.S.; Lamme, V.A.F. Masking disrupts reentrant processing in human visual cortex. J. Cognit. Neurosci. 2007, 19, 1488-1497. [CrossRef] [PubMed] 
25. Lamme, V.A.F. Separate neural definitions of visual consciousness and visual attention: A case for phenomenal awareness. Neural Netw. 2004, 17, 861-872. [CrossRef] [PubMed]

26. Lamme, V.A.F.; Roelfsema, P. The distinct modes of vision offered by feedforward and recurrent processing. Trends Neurosci. 2000, 23, 571-579. [CrossRef]

27. Supèr, H.; Spekreijse, H.; Lamme, V.A.F. Two distinct modes of sensory processing observed in monkey primary visual cortex (V1). Nat. Neurosci. 2001, 4, 304-310. [CrossRef] [PubMed]

28. Juan, C.-H.; Campana, G.; Walsh, V. Cortical interactions in vision and awareness: Hierarchies in reverse. Prog. Brain Res. 2004, 144, 117-130. [PubMed]

29. Pascual-Leone, A.; Walsh, V. Fast backprojections from the motion to the primary visual area necessary for visual awareness. Science 2001, 292, 510-512. [CrossRef] [PubMed]

30. Silvanto, J.; Lavie, N.; Walsh, V. Double dissociation of V1 and V5/MT activity in visual awareness. Cereb. Cortex 2005, 15, 1736-1741. [CrossRef] [PubMed]

31. Ro, T.; Breitmeyer, B.; Burton, P.; Singhai, N.S.; Lane, D. Feedback con- tributions to visual awareness in human occipital cortex. Curr. Biol. 2003, 14, 1038-1041. [CrossRef]

32. Thielscher, A.; Reichenback, A.; Uðurbil, K.; Uludağ, K. The cortical site of visual suppression by transcranial magnetic stimulation. Cereb. Cortex 2010, 20, 328-338. [CrossRef] [PubMed]

33. Koivisto, M.; Mäntylä, T.; Silvanto, J. The role of early visual cortex (v1/v2) in conscious and unconscious visual perception. Neuroimage 2010, 51, 828-834. [CrossRef] [PubMed]

34. Boyer, L.L.; Harrison, S.; Ro, T. Unconscious processing of orientation and color without primary visual cortex. Proc. Natl. Acad. Sci. USA 2005, 102, 16875-16879. [CrossRef] [PubMed]

35. Pockett, S. On subjective back-referral and how long it takes to become conscious of a stimulus: A reinterpretation of Libet's data. Conscious. Cognit. 2002, 11, 144-161. [CrossRef]

36. Pockett, S. Backwards referral, flash lags and quantum free will: A response to commentaries on papers by Pockett, Klein, Gomes and Trevena \& Miller. Conscious. Cognit. 2002, 11, 342-344.

37. Brascamp, J.; Blake, R.; Knapen, T. Negligable front-parietal bold activity accompanying unreportable switches in bistable perception. Nat. Neurosci. 2015, 18, 1672-1678. [CrossRef] [PubMed]

38. Frässle, S.; Sommer, J.; Jansen, A.; Naber, M.; Einhäuser, W. Binocular rivalry: Frontal activity relates to introspection and action but not to perception. J. Neurosci. 2014, 34, 1738-1747. [CrossRef] [PubMed]

39. Boly, M.; Massimini, M.; Tsuchiya, N.; Postle, B.R.; Koch, C.; Tononi, G. Are the neural correlates of consciousness in the front or the back of the Cereb. Cortex? Clinical and neuroimaging evidence. J. Neurosci. 2017, 37, 9603-9613. [CrossRef] [PubMed]

40. Tsuchiya, N.; Wilke, M.; Frässle, S.; Lamme, V.A.F. No-report paradigms: Extracting the true neural correlates of consciousness. Trends Cognit. Sci. 2015, 19, 757-770. [CrossRef] [PubMed]

41. Pitts, M.A.; Padwal, J.; Fennelly, D.; Martinez, A.; Hillyard, S.A. Gamma band activity and the P3 reflect post-perceptual processes, not visual awareness. Neuroimage 2014, 101, 337-350. [CrossRef] [PubMed]

42. Odegaard, B.; Knight, R.T.; Lau, H. Should a few null findings falsify prefrontal theories of conscious perception? J. Neurosci. 2017, 37, 9593-9602. [CrossRef] [PubMed]

43. Knight, R.T. Aging decreases auditory event-related potentials to unexpected stimuli in humans. Neurobiol. Aging 1987, 8, 109-113. [CrossRef]

44. Inui, K.; Wng, X.; Tamura, Y.; Kaneoke, Y.; Kakigi, R. Serial processing in the human somatosensory system. Cereb. Cortex 2004, 14, 851-857. [CrossRef] [PubMed]

45. Moutard, C.; Dehaene, S.; Malach, R. Spontaneous fluctuations and non-linear ignitions: Two dynamic faces of cortical recurrent loops. Neuron 2015, 88, 194-206. [CrossRef] [PubMed]

46. Salami, M.; Itami, C.; Tsumoto, T.; Kimura, F. Change of conduction velocity by regional myelination yeilds constant latency irrespective of distance between thalamus and cortex. Proc. Natl. Acad. Sci. USA 2003, 100, 6174-6179. [CrossRef] [PubMed]

47. Anderson, J.C.; Martin, K.A.C. Connection from cortical area V2 to V3a in macaque monkey. J. Comp. Neurol. 2005, 488, 320-330. [CrossRef] [PubMed]

48. He, S.; Cavanagh, P.; Intilligator, J. Attentional resolution and the locus of visual awareness. Nature 1996, 383, 334-337. [CrossRef] [PubMed]

49. He, S.; MacLeod, D.I. Orientation-selective adaptation and tilt after-effect from invisible patterns. Nature 2001, 411, 473-476. [CrossRef] [PubMed] 
50. Cumming, B.G.; Parker, A. Responses of primary visual cortical neurons to binocular disparity without depth perception. Nature 1997, 389, 280-283. [CrossRef] [PubMed]

51. Gawne, T.J.; Martin, J.M. Activity of primate V1 cortical neurons during blinks. J. Neurophysiol. 2000, 84, 2691-2694. [PubMed]

52. Martinez-Conde, S.; Macknik, S.L.; Hubel, D.H. Microsaccadic eye movements and firing of single cells in the striate cortex of macaque monkeys. Nat. Neurosci. 2000, 3, 251-258. [CrossRef] [PubMed]

53. Gur, M.; Snodderly, D.M. A dissociation between brain activity and perception: Chromatically opponent cortical neurons signal chromatic flicker that is not perceived. Vis. Res. 1997, 37, 377-382. [CrossRef]

54. Sheinberg, D.L.; Logothetis, N.K. The role of temporal cortical areas in perceptual organization. Proc. Natl. Acad. Sci. USA 1997, 94, 3408-3413. [CrossRef] [PubMed]

55. Polonsky, A.; Blake, R.; Braun, J.; Heeger, D.J. Neuronal activity in human primary visual cortex correlates with perception during binocular rivalry. Nat. Neurosci. 2000, 3, 1153-1159. [CrossRef] [PubMed]

56. Tong, F.; Engel, S.A. Interocular rivalry revealed in the human cortical blind-spot representation. Nature 2001, 411, 195-199. [CrossRef] [PubMed]

57. Wilke, M.; Logothetis, N.K.; Leopold, D.A. Local field potential reflects perceptual suppression in monkey visual cortex. Proc. Natl. Acad. Sci. USA 2006, 103, 17507-17512. [CrossRef] [PubMed]

58. Buzsáki, G.; Anastassiou, C.A.; Koch, C. The origin of extracellular fields and currents-EEG, ECoG, LFP and spikes. Nat. Rev. Neurosci. 2012, 13, 407-420. [CrossRef] [PubMed]

59. Einevoll, G.T.; Kayser, C.; Logothetis, N.K.; Panzeri, S. Modelling and analysis of local field potentials for studying the function of cortical circuits. Nat. Rev. Neurosci. 2013, 14, 770-785. [CrossRef] [PubMed]

60. Adey, W.R. Tissue interactions with nonionizing electromagnetic fields. Physiol. Rev. 1981, 61, 435-514. [PubMed]

61. Richardson, T.L.; Turner, R.W.; Miller, J.J. Extracellular fields influence transmembrane potentials and synchronization of hippocampal neuronal activity. Brain Res. 1984, 294, 255-262. [CrossRef]

62. Turner, R.W.; Richardson, T.L.; Miller, J.J. Ephaptic interactions contribute to paired pulse and frequency potentiation of hippocampal field potentials. Exp. Brain Res. 1984, 54, 567-570. [CrossRef] [PubMed]

63. Dudek, F.E.; Snow, R.W.; Taylor, C.P. Role of electrical interactions in synchronization of epileptiform bursts. Adv. Neurol. 1986, 44, 593-617. [PubMed]

64. Taylor, C.P.; Krnjevic, K.; Ropert, N. Facilitation of hippocampal CA3 pyramidal cell firing by electrical fields generated antidromically. Neuroscience 1984, 11, 101-109. [CrossRef]

65. Snow, R.W.; Dudek, F.E. Evidence for neuronal interactions by electrical field effects in the CA3 and dentate regions of rat hippocampal slices. Brain Res. 1986, 367, 292-295. [CrossRef]

66. Dalkara, T.; Krnjevic, K.; Ropert, N.; Yim, C.Y. Chemical modulation of ephaptic interaction of CA3 hippocampal pyramids. Neuroscience 1986, 17, 361-370. [CrossRef]

67. Yim, C.Y.; Krnjevic, K.; Dalkara, T. Ephaptically generated potentials in CA1 neurons of rat's hippocampus in situ. J. Neurophysiol. 1986, 56, 99-122. [PubMed]

68. Faber, D.S.; Korn, H. Electrical field effects: Their relevance in central neural networks. Physiol. Rev. 1989, 69, 821-863. [PubMed]

69. Frölich, F.; McCormick, D. Endogenous electric fields may guide neocortical activity. Neuron 2010, 67, 129-143. [CrossRef] [PubMed]

70. Pockett, S. The electromagnetic field theory of consciousness: A testable hypothesis about the characteristics of conscious as opposed to non-conscious fields. J. Conscious. Stud. 2012, 19, 191-223.

71. Pockett, S. Initiation of intentional actions and the electromagnetic field theory of consciousness. Humana Mente 2011, 15, 159-175.

72. Pockett, S.; Zhou, Z.Z.; Brennan, B.J.; Bold, G.E.J. Spatial resolution and the neural correlates of sensory experience. Brain Topogr. 2007, 20, 1-6. [CrossRef] [PubMed]

73. Pockett, S. Brain basis of voluntary control. In Reference Module in Neuroscience and Biobehavioral Psychology; Elsevier: Amsterdam, The Netherlands, 2017; pp. 1-9.

74. Pockett, S. Does consciousness cause behaviour? J. Conscious. Stud. 2004, 11, 23-40.

75. Pockett, S. The concept of free will: Philosophy, neuroscience and the law. Behav. Sci. Law 2007, 25, 281-293. [CrossRef] [PubMed]

76. Pockett, S.; Banks, W.P.; Gallagher, S. Does Consciousness Cause Behavior? MIT Press: Cambridge, MA, USA, 2006; p. 364. 
77. Pockett, S.; Banks, W.P.; Gallagher, S. Editors' introduction. In Does Consciousness Cause Behavior? Pockett, S., Banks, W.P., Gallagher, S., Eds.; MIT Press: Cambridge, MA, USA, 2006; pp. 1-6.

78. Pockett, S.; Purdy, S.C. Are voluntary movements initiated preconsciously? The relationships between readiness potentials, urges and decisions. In Conscious Will and Responsibility; Sinnot-Armstrong, W., Nadel, L., Eds.; Oxford University Press: New York, NY, USA, 2011; pp. 34-46.

79. Wegner, D.M.; Wheatley, T. Apparent mental causation: Sources of the experience of will. Am. Psychol. 1999, 54, 480-492. [CrossRef] [PubMed]

80. Wegner, D.M.; Sparrow, B.; Winerman, L. Vicarious agency: Experiencing control over the movements of others. J. Pers. Soc. Psychol. 2004, 86, 838-848. [CrossRef] [PubMed]

81. Kajikawa, Y.; Schroeder, C.E. How local is the local field potential? Neuron 2011, 72, 847-858. [CrossRef] [PubMed]

82. Newell, B.R.; Shanks, D.R. Unconscious influences on decision making: A critical review. Behav. Brain Sci. 2014, 37, 1-61. [CrossRef] [PubMed]

83. Tononi, G.; Srinivasan, R.; Russell, D.P.; Edelman, G.M. Investigating neural correlates of conscious perception by frequency- tagged neuromagnetic responses. Proc. Natl. Acad. Sci. USA 1998, 95, 3198-3203. [CrossRef] [PubMed]

84. Pockett, S.; Brennan, B.J.; Bold, G.E.J.; Holmes, M.D. A possible physiological basis for the discontinuity of consciousness. Front. Psychol. 2011, 2. [CrossRef] [PubMed]

85. Pockett, S.; Purdy, S.C.; Brennan, B.J.; Holmes, M.D. Auditory click stimuli evoke event-related potentials in the visual cortex. Neuroreport 2013, 24, 837-840. [CrossRef] [PubMed]

86. Freeman, W.J.; Baird, B. Relation of olfactory EEG to behavior: Spatial analysis. Behav. Neurosci. 1986, 101, 393-408. [CrossRef]

87. Freeman, W.J.; Grajski, K.A. Relation of olfactory EEG to behavior: Factor analysis. Behav. Neurosci. 1987, 101, 766-777. [CrossRef] [PubMed]

88. Freeman, W.J.; van Dijk, B.W. Spatial patterns of visual cortical fast EEG during conditioned reflex in a rhesus monkey. Brain Res. 1987, 422, 267-276. [CrossRef]

89. Freeman, W.J.; Viana di Prisco, G. Relation of olfactory EEG to behavior: Time series analysis. Behav. Neurosci. 1986, 100, 753-763. [CrossRef] [PubMed]

90. Finkel, A.S.; Redman, S. Theory and operation of a single microelectrode voltage clamp. J. Neurosci. Methods 1984, 11, 101-127. [CrossRef]

91. Cole, K.S. Dynamic electrical characteristics of the squid axon membrane. Arch. Sci. Physiol. 1949, 3, $253-258$.

92. Barlow, H.B. Single units and sensation: A neuron doctrine for perceptual psychology? Perception 1972, 1, 371-394. [CrossRef] [PubMed]

93. Gross, C.G. Genealogy of the "grandmother cell". Neuroscientist 2002, 8, 512-518. [CrossRef] [PubMed]

94. Connor, C.E. Friends and grandmothers. Nature 2005, 435, 1036-1037. [CrossRef] [PubMed]

95. Hubel, D.H.; Wiesel, T.N. Receptive fields of single neurones in the cat's striate cortex. J. Physiol. 1959, 148, 574-591. [CrossRef] [PubMed]

96. Hubel, D.H.; Wiesel, T.N. Receptive fields and functional architecture in two non-striate visual areas (18 and 19) of the cat. J. Neurophysiol. 1965, 28, 229-289. [PubMed]

97. Barlow, H.B.; Levick, W.R. The mechanism of directionally selective units in rabbit's retina. J. Physiol. 1965, 178, 477-504. [CrossRef] [PubMed]

98. Leopold, D.A.; Logothetis, N.K. Activity changes in early visual cortex reflect monkeys' percepts during binocular rivalry. Nature 1996, 379, 549-553. [CrossRef] [PubMed]

99. Logothetis, N.K.; Schall, J.D. Neuronal correlates of subjective visual perception. Science 1989, 245, 761-763. [CrossRef] [PubMed]

100. Quiroga, R.Q.; Reddy, L.; Kreiman, G.; Koch, C.; Fried, I. Invariant visual representation by single neurons in the human brain. Nature 2005, 435, 1102-1107. [CrossRef] [PubMed]

101. Blake, R.; Cormack, R. On utrocular discrimination. Percept. Psychophys. 1979, 26, 53-68. [CrossRef]

102. Rees, G. Neural correlates of the contents of visual awareness in humans. Philos. Trans. R. Soc. B 2007, 362, 877-886. [CrossRef] [PubMed]

103. Maier, A.; Wilke, M.; Aura, C.; Zhu, C.; Ye, F.Q.; Leopold, D.A. Divergence of fmri and neural signals in V1 during perceptual suppression in the awake monkey. Nat. Neurosci. 2008, 11, 1193-1200. [CrossRef] [PubMed] 
104. Lutz, A.; Lachaux, J.P.; Martineries, J.; Varela, F.J. Guiding the study of brain dynamics by using first-person data: Synchrony patterns correlate with ongoing conscious states during a simple visual task. Proc. Natl. Acad. Sci. USA 2002, 99, 1586-1591. [CrossRef] [PubMed]

105. Melloni, L.; Molina, C.; Pena, M.; Torres, D.; Singer, W.; Rodriguez, E. Synchronization of neural activity across cortical areas correlates with conscious perception. J. Neurosci. 2007, 27, 2856-2858. [CrossRef] [PubMed]

106. Gaillard, R.; Dehaene, S.; Adam, C.; Clémenceau, S.; Hasboun, D.; Baulac, M.; Cohen, L.; Naccache, L. Converging intracranial markers of conscious access. PLoS Biol. 2009, 7. [CrossRef] [PubMed]

107. Tallon-Baudry, C. The roles of gamma-band oscillatory synchrony in human visual cognition. Front. Biosci. 2009, 14, 321-332. [CrossRef]

108. Pockett, S.; Bold, G.E.J.; Freeman, W.J. EEG synchrony during a perceptual-cognitive task: Widespread phase synchrony at all frequencies. Clin. Neurophysiol. 2009, 120, 695-708. [CrossRef] [PubMed]

109. Pockett, S.; Holmes, M.D. Intracranial EEG power spectra and phase synchrony during consciousness and unconsciousness. Conscious. Cognit. 2009, 18, 1049-1055. [CrossRef] [PubMed]

110. Luo, Q.; Mitchell, D.; Cheng, X.; Mondillo, K.; McCaffrey, D.; Holroyd, T.; Carver, F.; Coppola, R.; Blair, J. Visual awareness, emotion and gamma band synchronization. Cereb. Cortex 2009, 19, 1896-1904. [CrossRef] [PubMed]

111. Pockett, S. Problems with theories that equate consciousness with information or information processing. Front. Syst. Neurosci. 2014, 8. [CrossRef] [PubMed]

112. Hales, C.G.; Pockett, S. The relationship between local field potentials (LFPs) and the electromagnetic fields that give rise to them. Front. Syst. Neurosci. 2014, 8. [CrossRef]

(C) 2017 by the author. Licensee MDPI, Basel, Switzerland. This article is an open access article distributed under the terms and conditions of the Creative Commons Attribution (CC BY) license (http:/ / creativecommons.org/licenses/by/4.0/). 